adopted, in which, by means of a check list at the end, it is shown in what American libraries all the periodicals may be found. A good portion of the work is done in such works as have been mentioned: in the indexes to the literature of special subjects in the Smithsonian collections, in the publications of the Harvard University, and in the indexes to the publications of Societies, such as the Chemical, Geological, Zoological, Linnean, Astronomical, Geographical, Engineers, Statistical, the Society of Arts, and the Royal Society, and in the indexes of various periodicals. These should be systematically arranged; the chaos should be organized and classified, to enable the man of science to find out at a glance all that has been published on any branch of his subject, and the work would be of value to the country.

The range of subject-headings should include everything relating to scientific and technical subjects. These would include (taking Comte's classification for convenience in the serial arrangement), Mathematics, Astronomy, Physics, Chemistry, Physiology (or what is commonly understood as Natural History, with the generic term of Physiology or Physio-Philosophy), and Social Physics (including Sociology). These subjects are clear, well defined, and well known to the librarians.

There is nothing so necessary as that scientific thought and method should be embodied, classified, and arranged, preliminary to its organization as a whole. It would quicken the slow process of improvement that has extended over a thousand years. It is wonderful that it should be necessary to say this in the nineteenth century. The need for organization in all departments of science is keenly felt ; and the growth of Positivism in these latter days is one of the expressions of that need. Three centuries ago Bacon aimed at the organization of the sciences, holding that the sciences can be advanced only by combining them; that, as natural laws are invariable and uniform, "Physics being the mother of all science," so moral and civil philosophy could not flourish when separated from their roots in natural philosophy.

On national grounds it is necessary that this work should be done, for it is in the interest of the community generally, of the nation, that we should know what we possess. Public libraries and educational institutions are increasing; scientific experiment, discovery, and invention are increasing ; and the demand for such a subjectcatalogue will increase. Its value to the community would be inestimable. If it is thought advisable that the Royal Society or the Society of Arts should take the work in hand, the work should be subsidized by the Government, for the simple reason that it would be of national value. Scientific research is not so remunerative but that the student may fairly expect facility of access to the labours of those who have gone before. The want of a serviceable key to the vast body of scientific work contained in our literature is daily experienced by cultivators of science. There is a serious necessity that this material should be made more readily accessible for comparison, for verification, and for improvement. Much of it is a monument of shattered hopes, the unsuccessful efforts of poverty and despair; but all of it is suggestive to the earnest student.

No one Society or publisher can take the work in hand without Government support or benefaction. Attempts have been made, such as the attempt of the Royal Society, and that of Agassiz in his "Bibliographia Zoologiæ et Geologia," published by the Ray Society, which voluminous work, be it remembered, "was mainly compiled by the Professor for his own private use during the leisure moments of a life of almost incessant scientific research." In whatever hands the work may be placed, there is no doubt that the co-operation of the scientific Societies might be relied upon. With regard to the question of assistance from the Government, the following
Minute of the Lords Commissioners of Her Majesty's Treasury, dated November 28, I864, referring to the Royal Society's Catalogue, is very suggestive :-

"Having regard to the importance of the work with reference to the promotion of scientific knowledge generally, to the high authority of the source from which it comes, and to the labour gratuitously given by members of the Royal Society to its production, my Lords consider themselves justified in having the work printed at the cost of the public, with the understanding that, reserving such a number of copies for presentation as my Lords, in communication with the President of the Royal Society, may hereafter determine, the work shall be sold at such a price as may be calculated will repay the cost of printing.

"Their Lordships, however, desire it to be understood that the work shall go forth to the public under the authority of the Royal Society, by the exertions of whose members this important aid to the study of science has been produced."

J. TAYLOR KAY.

\section{IRIDESCENT CRYSTALS.I}

$\mathrm{THE}$ principal subject of the lecture is the peculiar coloured reflection observed in certain specimens of chlorate of potash. Reflection implies a high degree of discontinuity. In some cases, as in decomposed glass, and probably in opals, the discontinuity is due to the interposition of layers of air; but, as was proved by Stokes, in the case of chlorate crystals the discontinuity is that known as twinning. The seat of the colour is a very thin layer in the interior of the crystal and parallel to its faces.

The following laws were discovered by Stokes:-

(I) If one of the crystalline plates be turned round in its own plane, without alteration of the angle of incidence, the peculiar reflection vanishes twice in a revolution, viz. when the plane of incidence coincides with the plane of symmetry of the crystal. [Shown.]

(2) As the angle of incidence is increased the reflected light becomes brighter and rises in refrangibility. [Shown.]

(3) The colours are not due to absorption, the trans mitted light being strictly complementary to the reflected.

(4) The coloured light is not polarized. It is produced indifferently whether the incident light be common light or light polarized in any plane, and is seen whether the reflected light be viewed directly or through a Nicol's prism turned in any way. [Shown.]

(5) The spectrum of the reflected light is frequently found to consist almost entirely of a comparatively narrow band. When the angle of incidence is increased, the band moves in the direction of increasing refrangibility, and at the same time increases rapidly in width. In many cases the reflection appears to be almost total.

In order to project these phenomena a crystal is prepared by cementing a smooth face to a strip of glass, whose sides are not quite parallel. The white reflection from the anterior face of the glass can then be separated from the real subject of the experiment.

A very remarkable feature in the reflected light remains to be noticed. If the angle of incidence be small, and if the incident light be polarized in or perpendicularly to the plane of incidence, the reflected light is polarized in the opposite manner. [Shown.]

Similar phenomena, except that the reflection is white, arc exhibited by crystals prepared in a manner described by Madan. If the crystal be heated beyond a certain point the peculiar reflection disappears, but returns upon cooling. [Shown.]

In all these cases there can be little doubt that the reflection takes place at twin surfaces, the theory of such reflection (Phil. Mag., Sept. 1888) reproducing with re-

${ }^{1}$ Abstract of the Friday evening lecture delivered by Lord Rayleigh, F.R.S. at the Royal Institution on April 12, 1889. 
markable exactness most of the features above described. In order to explain the vigour and purity of the colour reflected in certain crystals, it is necessary to suppose that there are a considerable number of twin surfaces disposed at approximate equal intervals. At each angle of incidence there would be a particular wave-length for which the phases of the several reflections are in agreement. The selection of light of a particular wave-Iength would thus take place upon the same principle as in diffraction spectra, and might reach a high degree of perfection.

In illustration of this explanation an acoustical analogue is exhibited. The successive twin planes are imitated by parallel and equi-distant disks of muslin (Figs. I and 2) stretched upon brass rings and mounted (with the aid of three lazy-tongs arrangements), so that there is but one degree of freedom to move, and that of such a character as to vary the interval between the disks without disturbing their equi-distance and parallelism.

The source of sound is a bird-call, giving a pure tone of high pitch (inaudible), and the percipient is a high-pressure flame issuing from a burner so oriented that the direct waves are without influence upon the flame (see NATURE, xxxviii. 208; Proc. Roy. Inst., January 1 888). But the waves reflected from the muslin arrive in the effective direction, and if of sufficient intensity induce flaring. The experiment consists in showing that the action depends upon the distance between the disks. If the distance be such that the waves reflected from the several disks co-operate, the flame flares, but for intermediate adjustments recovers its equilibrium. For full success it is necessary

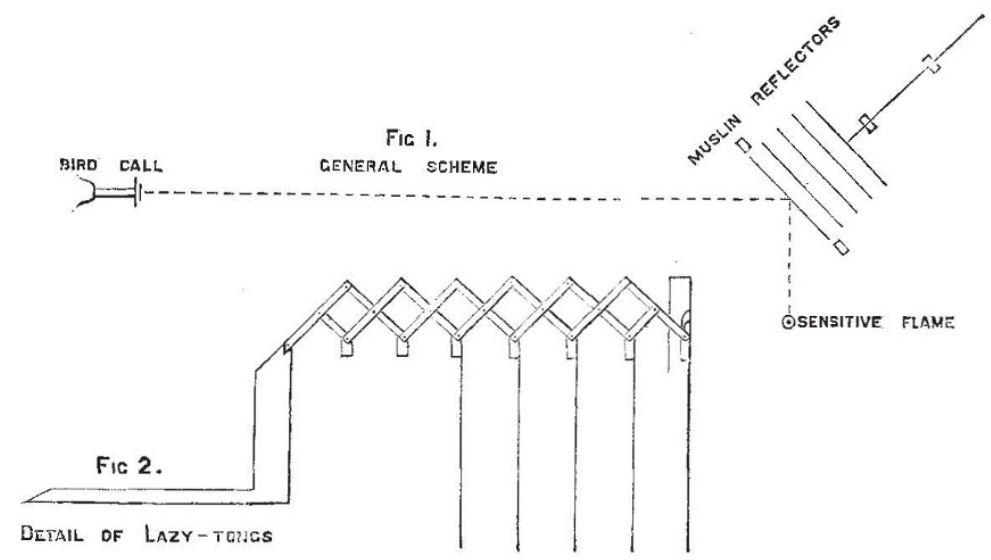

that the reflective power of a single disk be neither too great nor too small. A somewhat open fabric appears suitable.

It was shown by Brewster that certain natural specimens of Iceland spar are traversed by thin twin strata. A convergent beam, reflected at a nearly grazing incidence from the twin planes, depicts upon the screen an arc of light, which is interrupted by a dark spot corresponding to the plane of symmetry. [Shown.] A similar experiment may be made with small rhombs in which twin layers have been developed by mechanical force after the manner of Reusch.

The light reflected from fiery opals has been shown by Crookes to possess in many cases a high degree of purity,

\section{NOTES.}

THE thirty-eighth meeting of the American Association for the Advancement of Science will be held at Toronto. On Tuesday, August 27, at ncon, a meeting of the Council will be held at the Queen's Hotel, where will be the hotel head-quarters of the Association. On Wednesday, August 28, the first general session will begin at ro o'clock in the forenoon in the Convocation Hall, University Buildings. After the adjournment of the general session, the several Sections will organize. In the afternoon the Vice-Presidents will give their addresses before their respective Sections, and in the evening there will be a general session, when the retiring President, Major J. W. Powell, will deliver his address. The sessions will continue until the Tuesday evening following, and on Wednesday morning, September 4, a meeting of the Council will be held. Saturday, August 3I, will be devoted to excursions. The ineeting will close with excursions extending to September 7 . The general sessions and the meetings of the Sections will be held in the University Buildings, where also will be the offices of the local committee and of the permanent secretary during the meeting. rivalling in this respect the reflection from chlorate of potash. The explanation is to be sought in a periodic stratified structure. But the other features differ widely in the two cases. There is here no semicircular evanescence, as the specimen is rotated in azimuth. On the contrary, the coloured light transmitted perpendicularly through a thin plate of opal undergoes no change when the gem is turned round in its own plane. This appears to prove that the alternate states are not related to one another as twin crystals. More probably the alternate strata are of air, as in decomposed glass. The brilliancy of opals is said to be readily affected by atmospheric conditions.
Science states that arrangements have been made for a discussion in Section B on the "Relative Merits of the Dynamometric and Magnetic Methods of obtaining Absolute Measurements of Electric Currents." Prof. Thomas Gray, of the Rose Polytechnic Institute, will open the discussion with a paper on the subject, and he will exhibit one or more of Sir William Thomson's most recent forms of electric balance. Arrangements have been made by the local committee for the proper care and exhibition of instruments and specimens.

EFForTs are being made by the American Association for the Advancement of Science to form a National Chemical Society, with its head-quarters at Washington. A meeting will be held to consider the matter during the session of the American Association at Toronto.

THE annual general meeting of the Marine Biological Association was held in the rooms of the Royal Society on the 26th ult. In the absence of Prof. Huxley, the chair was taken by Sir E. Bowman, and there were present, among others, Lord

${ }^{\mathrm{I}}$ If the reflection were perpendicular, the interval between successive disks would be equal to the half wave-length, or to some multiple of this. 